Volume 8, No.1.5, 2019

International Journal of Advanced Trends in Computer Science and Engineering

Available Online at http://www.warse.org/IJATCSE/static/pdf/file/ijatcse5781.53019.pdf

https://doi.org/10.30534/ijatcse/2019/5781.52019

\title{
Android Based Chatting Application Using Firebase for Facilitating The Communication Among Indonesian Police Force Members
}

\author{
Vincent Angelo $^{1}$, Benny Hardjono ${ }^{2}$, Frans Panduwinata ${ }^{3}$, Andree E. Widjaja ${ }^{4}$, Aditya R. Mitra ${ }^{5}$ \\ ${ }^{1}$ Department of Informatics, Universitas Pelita Harapan, Indonesia, vincentangelo96@ yahoo.com \\ ${ }^{2}$ Department of Informatics, Universitas Pelita Harapan, Indonesia, benny.hardjono@uph.edu \\ ${ }^{3}$ Department of Informatics, Universitas Pelita Harapan, Indonesia, frans.panduwinata@uph.edu \\ ${ }^{4}$ Department of Information System, Universitas Pelita Harapan, Indonesia, andree.widjaja@uph.edu \\ ${ }^{5}$ Department of Information System, Universitas Pelita Harapan, Indonesia, aditya.mitra@uph.edu
}

\begin{abstract}
Humans are social being that need to communicate regularly. One of the common methods to communicate is to take advantage of the advancement of the digital technology such as chatting application. Nowadays, the communication among police force members, especially in Indonesia is somewhat limited due to the inadequate method of communicating available to them. Therefore, to utilize the current digital technology, it might be necessary to develop a chatting application which has some functions to facilitate the police force members to communicate among themselves and assist their jobs while they are in duty. Such chatting application was developed using Android Studio IDE and Firebase Database. Police force members could use this application to do several things, such as: communicating among the members, imposing warnings, and issuing tickets to the traffic offenders. Furthermore, there is also a Text Recognition API functioned as a license plate number scanner, which is useful for public use. For instance, to check a license plate number before buying a vehicle of interest. This current paper will report and elaborate the development process of our developed application.
\end{abstract}

Key words: Communication, chatting application, Indonesian police force, firebase

\section{INTRODUCTION}

Humans are social beings who have an indispensable need to communicate with each other. Along with the advancement of information technology, humans' needs for communication have also been altered. In the present time, the way and how humans communicate is not only limited to direct physical contact (face-to-face) communication, but it can also be conducted using digital technology through some online chatting applications, such as WhatsApp, Telegram, WeChat, Facebook Messenger, Snap Chat, Line, and others.

There are numerous types of communication that can be used in a chatting application, such as, texts, voices, pictures, and videos. It is known that instant messaging has been widely used by many people in the world since it is very fast, convenient, and easy to use. Meanwhile, police force members who carry out their activities in the field indeed require effective and efficient ways of communication. Such communication is mainly used by police force members to share information as well as to assist them with the matters pertaining to their official duties. However, the way the police force members communicate might be considered obsolete, particularly in Indonesia (for instance, by solely making use of walkie-talkie, phone call, or even pager). Therefore, drawing from the aforementioned problem statements, a chatting application that is specially designed for Indonesian police force members will be developed. The research in this work has a few advantages, as fully covered in the related study. Two of them are: 1) our mobile application requires no extra equipment on the police-vehicle, 2) it can used by public too.

The main purpose of this paper is to elaborate and discuss the development of an Android-based chatting application that is intended to facilitate the communication among Indonesian police force members while carrying out their duties. This application would allow the police force members, with specific user installation via database authorization, to communicate with each other efficiently, and it also has a special function to impose a warning or a ticket (fine) to the traffic offenders. Moreover, this application in another installation scheme, would also allow the public (ordinary user), to check a number plate against police database of stolen vehicles, for instance, as an assistance or tool in buying a second hand.

\section{THEORETICAL BASIS AND LITERATURE REVIEW}

This part will discuss some theories and the literature reviews (related to digital technologies) incorporated in this study. The sub section will be divided into 9 parts, namely Smartphone and Related Study, Android, Java Programming, Chatting 
Vincent Angelo et al., International Journal of Advanced Trends in Computer Science and Engineering, 8(1.5), 2019, 347- 354

\subsection{Smartphone and Related Studies}

Smartphone is mobile smart cellular phones equipped with the latest and advanced digital technological features like a functional computer. A Smartphone has an operating system (OS) software (Android or iOS) to provide some standard and basic relationships for application developers. Smartphone also has some advanced features such as Email, Internet, e-book readers, and other applications [1]. Several similar mobile applications are available in advanced countries. For example the Police Infringement Notice System (PINS) [2] [1] created for Tasmania Police Australia, helps a police officer (but not for public use at all) in issuing tickets for a number of traffic offences. These tickets are then automatically sent to the offender via the post office. Another example is SmartCop [3] [2], a mobile application which requires its hardware in the form of Vehicular Ad hoc Networks (VANET) and its software to be installed on specially equipped vehicles.

Our work has addressed a number of these aspects, as well as, to continue our previous research with smartphone as nonintrusive traffic sensor [16], which will include the police force mobile application as an important additional feature. This related research includes: vehicle traffic monitoring, modelling [17], vehicle travel distance-travel time prediction [18] and vehicle counting [19] [20]. A research in Egypt [4] [3] has identified a number of advantages of mobile application of this kind. They are: reduced use of paper, reduced working hours use (as a number of tasks will be automated), reduced human error (when types of traffic violation can be chosen from a drop down menu), ticket citation can be accessed by other police officers (so multiple offences or even warning can be noticed immediately), reduced paper work time, improved commuter/client convenience and possible increase of revenue (as penalty must be paid via bank or on-line). Besides these, our application requires no extra equipment on the police vehicle, and can used by public too

\subsection{Android}

Android is an OS software for Smartphone. Android is an open source project called Android Open Source Project (AOSP). Google uses this project as the basis for creating their own Android version. As an OS, the task of Android is to be a translator between the user and the device. In short, Android would act and work like Windows OS, but it works only for mobile phones [5].

\subsection{Java Programming}

Java is an advanced programming language that allows programmers to write computer instructions using commands in English. Java is known as a high-level programming language as it can be read and written easily by humans. Like English, Java has several rules called syntax to determine how the instructions will be written [6].

\subsection{Chatting Application}

Chatting is a feature or a program on the Internet to communicate directly with internet users who are online together. This communication can be in a form of text (text chat) or voice (voice chat). Chatting is not only popular with teenagers or young people, but, it has also spread to older people. With using chat, we can freely talk about anything ranging from friendships, jobs, lessons in school, courses, even to the personal matters [7].

\subsection{Application Program Interface (API)}

Application Program Interface (API) is a code that allows two software programs to communicate with each other. The API determines the correct way for developers to write programs and requests services from the OS or other applications. The API is implemented by a function call consisting of verbs and nouns [8].

\subsection{Firebase}

Firebase is BaaS (Backend as a Service) own by Google. Firebase offers solution to facilitate Mobile Apps Developer job. With Firebase, apps developer can focus to develop an application without worrying about backend issues [9].

\subsection{MD5 and AES}

MD5 hashing algorithm is a one-way cryptographic function that accepts messages of any length as input and returns a digest value output with a predetermined length to be used to authenticate the original message. Meanwhile, The Advanced Encryption Standard (AES) is a cryptographic algorithm used to secure data. The AES algorithm can both encrypt and decrypt information [10] - [12]. Both MD5 and AES are implemented in the developed application.

\subsection{Unified Modelling Language}

Unified Modelling Language (UML) is a modelling language that consists of a collection of integrated diagrams. UML represents a collection of the best engineering practices that have proven successful in modelling of large and complex systems. UML is the most important part of developing object-based software and software development processes [13], therefor the analysis and system design of this application is following the UML methods. 


\subsection{White-Box and Black-Box Testing}

White-box testing is a test that considers the internal mechanism of a system or component [14]. Meanwhile, Black-Box Testing [15], also known as behavioural testing, is a testing method in which the internal structure, design, and implementation of the item tested is unknown to the examiners.

\section{SYSTEM DESIGN}

At this stage, the process involved in application development will be reported. The development process involved the user interface design, database system, the drawing of UML diagrams. The application was developed on Android Studio, using Java Programming Language. As for its database system, Firebase was used.

\subsection{Application Scheme}

The scheme represents the paths contained in this application. Figure 1 illustrates the scheme of the developed application. The name of the chatting application that was developed called "POTICK". There are several schemes ranging from installation schemes, schemes for admin, officers, and normal users. The installation scheme can be seen in Figure 1 below. A scheme is used to explain the process of how a user installs an application.

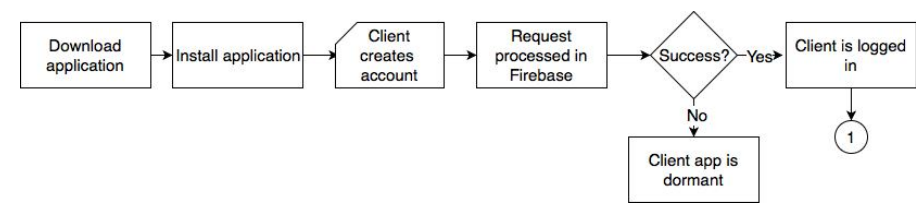

Figure 1: Application Installation Scheme

The next scheme is a scheme that explains the flow of the application that is tailored to the role of the user. Figure 2 describes the application scheme of users who have normal roles. Meanwhile, Figure 3 describes the application scheme for officers and Figure 4 illustrates the application scheme for the admin.

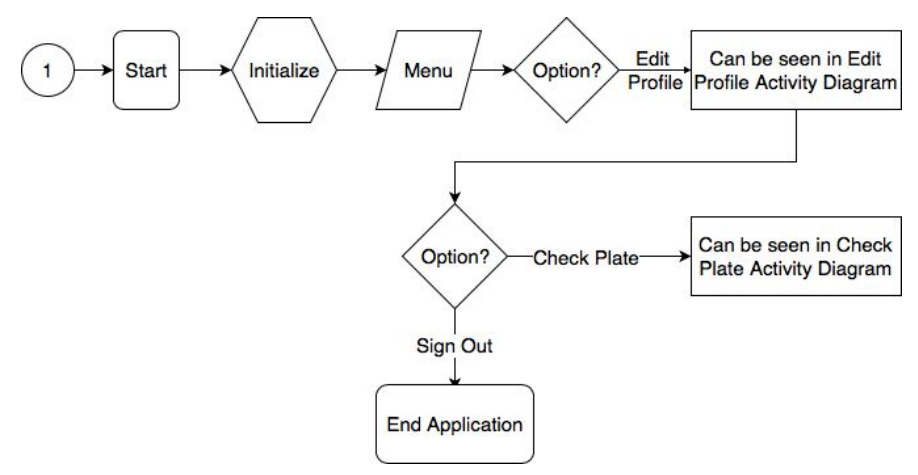

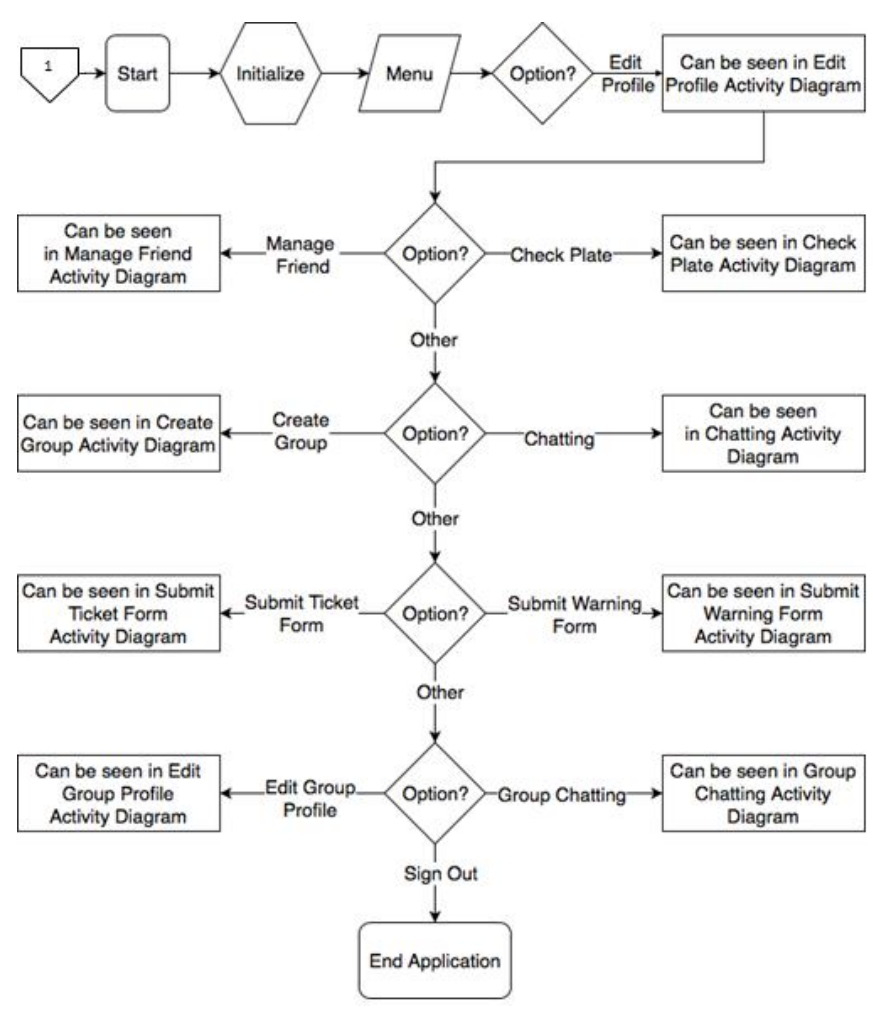

Figure 3: Application Scheme for a Police Officer

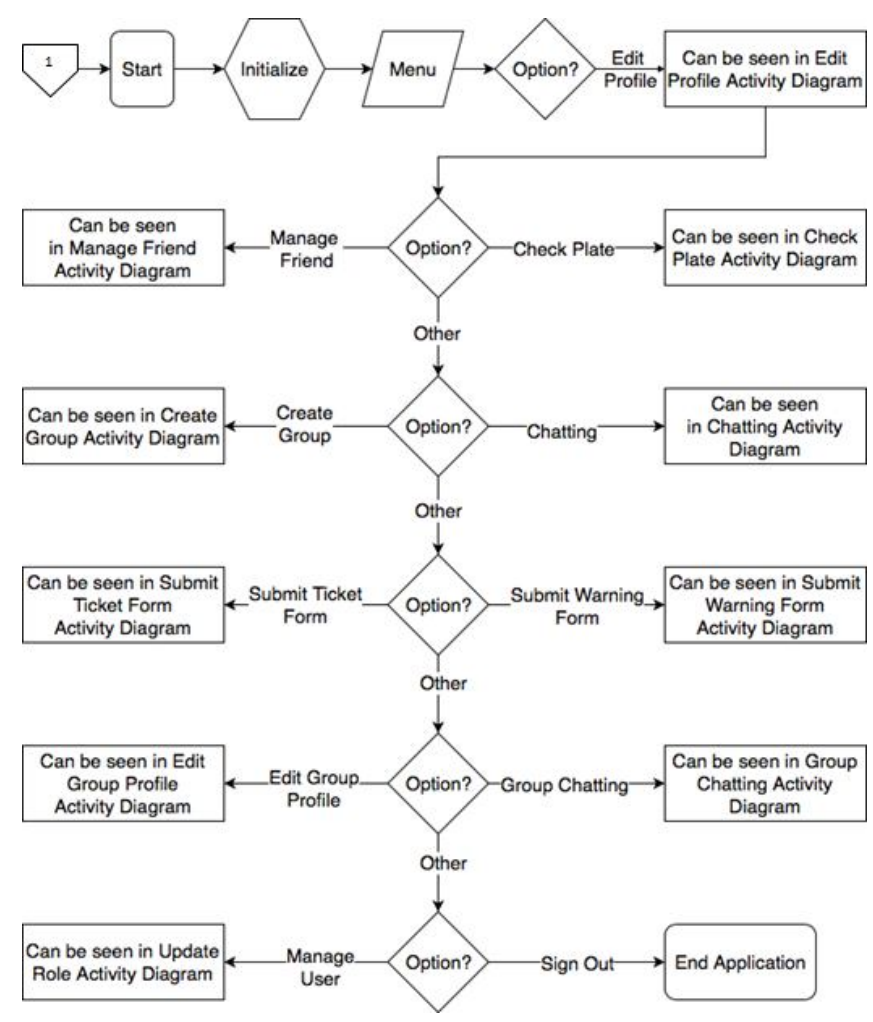

Figure 4: Application Scheme for the Administrator

Figure 2: Application Scheme for Ordinary User 


\subsection{Use Case Diagram}

There are 4 levels of users, they are Non-Registered/Public Users, Normal/Ordinary Users, Police Officers, and Admin. There are activities that can be accessed by the user, these activities include registration of a new account (Sign Up Account), Sign In, Edit Profile, Check License Plate, Manage Friend, Chat, Create Group, Submit Warning Form, Submit Ticketing Form, Chat Group, Edit Group Profile, and Role Update. There is a difference between activities that can be accessed by each level of the user. Non-Registered Users can only access the Sign-Up Account. User (Normal User) can only access the Sign-In Account, Edit Profile, and Check License Plate. Officers can access activities that can be accessed by normal users plus activities such as Manage Friend, Chat, Create Group, Submit Warning Form, Submit Ticketing Form, Chat Group, and Edit Group Profile. Admin can access things related to the back-end of the application, namely View Data, Manage Data, and Manage Users. Use case diagram of this application can be seen in Figure 5.

\subsection{Application Database Design}

All Firebase Database data is stored as a Java Script Object Notation (JSON) object. Unlike SQL databases, Firebase does not have tables or records. When we add data to a JSON tree, the data will become a node in the existing JSON structure with the associated key. The database on this application has several JSON trees, such as Users, Groups, Messages, Friends, Friend Requests, Warning, Ticket, and Notification. Table 1 lists a database design with attributes.

\subsection{Test Plan}

In this study, the White-Box Testing and Black-Box Testing methods were conducted. White-Box Testing was carried out by the people who understand the program and the contents of this application, the developer. There were several Case Tests that are used to ensure that all application functions can be run properly in accordance to the expected results. While Black-Box Testing was carried out by the people who do not know the contents of this application, the users (police force members).
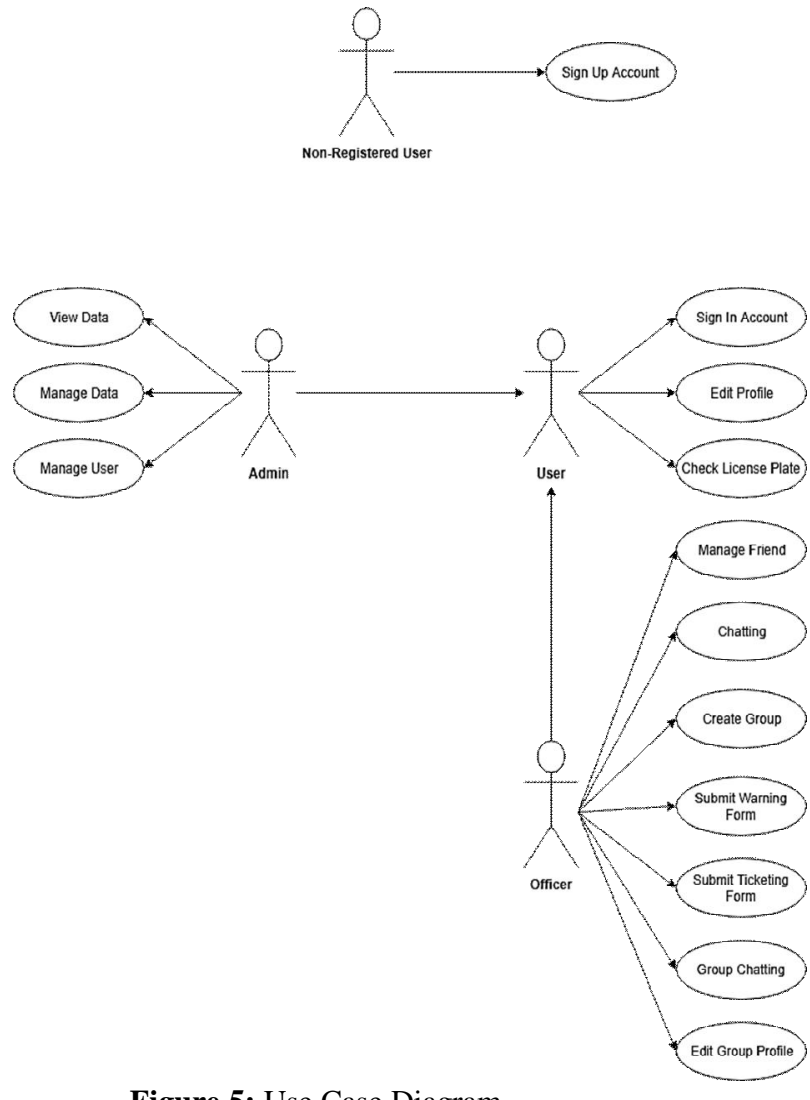

Figure 5: Use Case Diagram

Table 1: Database design with its attributes

\begin{tabular}{|c|c|c|}
\hline Table Name & Attributes Name & Data Type \\
\hline Users & $\begin{array}{c}\text { UID(PK), device_token, } \\
\text { email, image, name, } \\
\text { online, position,status, } \\
\text { thumb_image, username }\end{array}$ & String \\
\hline Groups & $\begin{array}{c}\text { GroupUID(PK), } \\
\text { groupImage, groupName, } \\
\text { UID, date }\end{array}$ & String \\
\hline Messages & $\begin{array}{c}\text { UID(PK), UID2, } \\
\text { MessageKey, message, } \\
\text { seen, sender, type }\end{array}$ & String \\
\hline $\begin{array}{c}\text { Messages } \\
\text { (Group) }\end{array}$ & $\begin{array}{r}\text { MessageKey, message, } \\
\text { seen, sender, type }\end{array}$ & String \\
\hline Friends & UID(PK), UID2, date & String \\
\hline $\begin{array}{c}\text { Friend } \\
\text { Requests }\end{array}$ & $\begin{array}{r}\text { UID(PK), UID2, } \\
\text { request_type }\end{array}$ & String \\
\hline Warning & $\begin{array}{c}\text { License Plate(PK), date, } \\
\text { location, officer, warned }\end{array}$ & String \\
\hline
\end{tabular}


Vincent Angelo et al., International Journal of Advanced Trends in Computer Science and Engineering, 8(1.5), 2019, 347- 354

\subsection{User Interface Design}

The following figures (Figure 6 - Figure 12) show the User Interface Design (UID) of the developed application (POTICK).

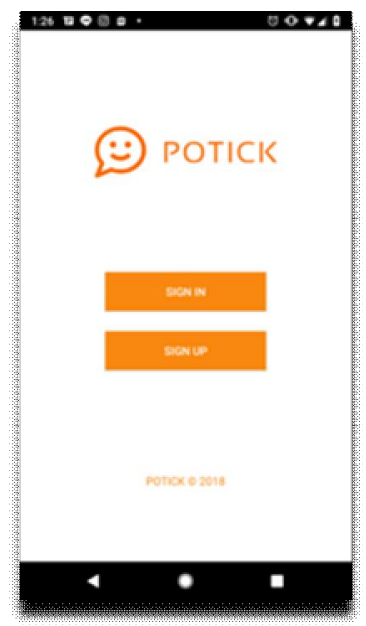

Figure 6: Home Page

Figure 6 shows the home page of the application. User can sign in if he/she already has an account, or sign up if one had already registered.

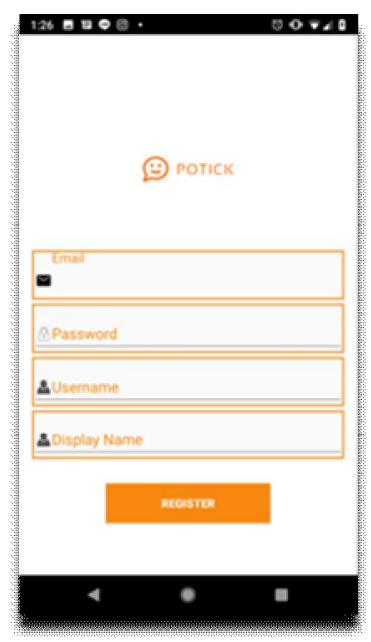

Figure 7: Sign Up Page

Figure 7 shows the sign-up page. User can fill the information in the required field. 


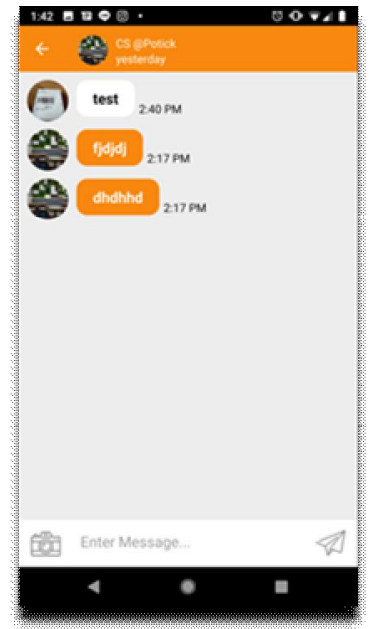

Figure 10: Chat Screen View

As shown by figure 10 , the chat function is an important feature of this application.

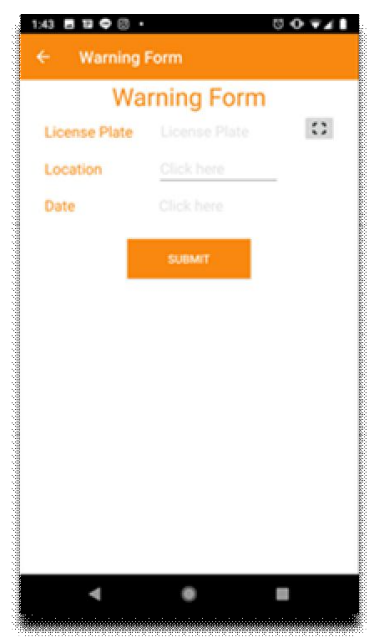

Figure 11: Submit Warning Form

Figure 11 shows the form to submit a warning regarding a suspected license plate. While, Figure 12 shows the form to submit ticketing. This is an important function for police officer to issue a fine/ticket to the traffic offenders.

\section{TESTING RESULTS}

From the tests that were carried out both using white-box and black-box testing method, all test cases (by testing all functions and features) were performed successfully. Black-box testing was conducted by 4 testers (police force members). Each tester did not know the internal or technical details of this developed application. Based on all of the testing results, it was thus concluded that the overall test was successful. In other words, the developed application has functioned properly.

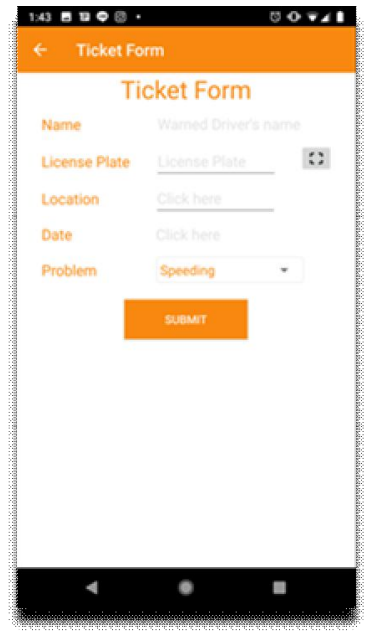

Figure 12: Submit Ticketing Form

\section{CONCLUSION}

The Chatting application for Android-based Smartphone to facilitate the communication among police force members has been successfully developed. The testing results of this application were also proven satisfactory. The developed application has several important features such as Sign Up, Sign In, Reset Password, Edit Profile, Chat, Create Group, Edit Group Profile, Group Chat, Submit Warning Form, Submit Ticket Form, Check Plate, and Role Update. The testing was carried out in the form of simulations using a Smartphone, and each of the main features of the application can run successfully as expected.

This developed application is ready to be implemented as an alternative communication among the Indonesian police force members. The application has several essential functions, such as Chatting, Group Chat, Submitting Warning, and Submitting Ticket. Since the application will store the valid and transparent related information, this developed application might be able to reduce the frauds which have often occurred in many ticketing cases, especially in Indonesia. Besides, public users can also use this application to check whether their vehicle has been issued a ticket or warning by the police force members. In addition, concerning the security of sensitive information that being sent over a medium is vital in the communication [16], as well as the importance of cryptographic [17], [21], [22], [23], [24] for security reasons, this developed application are equipped with MD5 hash algorithm and AES. Further work can be carried on other useful features, such as: checking the completion of fine payment and the application of merit and de-merit points for drivers[25]. 


\section{ACKNOWLEDGEMENT}

Much gratitude is expressed for the support from the Indonesian Ministry of Research Technology and Higher Education (RistekDikti), in a form of a competitive research grant scheme for Dr. Benny Hardjono (Corresponding Author) and his team, over the period of 2017 to 2019. The features developed in this work, in contract no. 020/AKM/MONOPNT/2019, are to be included in our mobile application to gather data for highway modelling, in the aforementioned-research.

\section{REFERENCES}

1. Maxmanroe. Pengertian smartphone, sistem operasi, fitur, jenis smartphone, maxmanroe.com, 2018. [Online]. Available: https://www.maxmanroe.com/vid/teknologi/mobile-app/ pengertian-smartphone.html. [Accessed: 11-Dec-2018].

2. Tasmania Police. Traffic FAQ - Tasmania Police, police.tas.gov.au, 2019. [Online]. Available: https://www.police.tas.gov.au/what-we-do/traffic-polici ng/traffic-faq/. [Accessed: 04-May-2019].

3. S. H. Ahmed, M. A. Yaqub, S. H. Bouk, and D. Kim. SmartCop: Enabling smart traffic violations ticketing in vehicular named data networks, Mobile Information Systems, vol. 16, 12 pages, May 2016. https://doi.org/10.1155/2016/1353290

4. H. Amer, R. Abd El Aziz, and M. Hamza. Investigating mobile traffic violation ticketing service in Egypt: The provider and user perspectives, International Journal of Management and Information Technology, vol. 10, no. 1, pp. 1776-1783, June 2014. https://doi.org/10.24297/ijmit.v10i1.650

5. C. Schmidt. What is Android? Here is a Complete Guide for Beginners, androidpit.com, 2016. [Online]. Available: https://www.androidpit.com/what-is-android. [Accessed: 06-Aug-2018].

6. P. Leahy. What is Java Computer Programming Language?, thoughtco.com, 2018. [Online]. Available: https://www.thoughtco.com/what-is-java-2034117.

[Accessed: 06-Aug-2018].

7. M. Rouse. What is Chatting?, techtarget.com, 2005. [Online]. Available: https://searchmicroservices.techtarget.com/definition/ch atting. [Accessed: 09-Dec-2018].

8. T. Nolle and T. Li. What is Application Program Interface (API)?, techtarget.com, 2017. [Online]. Available:

https://searchmicroservices.techtarget.com/definition/ap plication-program-interface-API. [Accessed: 15-Feb-2019].

9. C. Esplin. What is Firebase?, howtofirebase.com, $2016 . \quad$ [Online]. Available: https://howtofirebase.com/what-is-firebase-fcb8614ba44 2. [Accessed: 06-Aug-2018].
10. L. Peter. What is MD5?, techtarget.com, 2017. [Online]. Available: https://searchsecurity.techtarget.com/definition/MD5. [Accessed: 15-Feb-2019].

11. Zacky. Enkripsi Algoritma AES (Advanced Encryption Standard), Kriptografi \& Jaringan Komputer, 2016. [Online]. Available: http://kriptografijaringan.blogspot.com/2016/03/enkrips i-algoritma-aes-advanced.html. [Accessed: 06-Aug-2018].

12. NIST. Federal Information Processing Standards Publication 197 Announcing the Advanced Encryption Standard (AES), nist.gov, 2001. [Online]. Available: http://csrc.nist.gov/csor/. [Accessed: 06-Aug-2018].

13. Visual-paradigm. What is Unified Modelling Language (UML)?, visual-paradigm.com, 2018. [Online]. Available: https://www.visual-paradigm.com/guide/uml-unified-m odeling-language/what-is-uml/. [Accessed: 09-Dec-2018].

14. G. J. K. V. Wyk. White Box Testing, us-cert.gov, 2013. [Online]. Available: https://www.us-cert.gov/bsi/articles/best-practices/white -box-testing/white-box-testing. [Accessed: 09-Oct-2019].

15. Softwaretestingfundamentals. Black Box Testing Software Testing Fundamentals, Softwaretestingfundamentals.com, 2019. [Online]. Available:

http://softwaretestingfundamentals.com/black-box-testin g/. [Accessed: 06-Jan-2019].

16. B. Hardjono, A. Wibowo, M. F. Rachmadi, and W. Jatmiko. Mobile Phones as Traffic Sensors with Map Matching and Privacy Considerations, in Micro-Nano Human Science (MHS), pp. 450-455, 2012. https://doi.org/10.1109/MHS.2012.6492490

17. B. Hardjono. Calibration of Virtual Detection Zone and CCTV Data for Cell Transmission Model, in 9th IEEE International Conference on Sensing Technology (ICST), pp. 6, Dec 2015.

18. B. Hardjono, H. Tjahyadi, A. E. Widjaja, M. Gracio, and A. Rhizma. Vehicle Travel Distance and Time Prediction using Virtual Detection Zone and CCTV Data in 17th IEEE-ICCT, pp. 6, 2017 https://doi.org/10.1109/ICCT.2017.8359947

19. B. Hardjono, A. E. Widjaja, R. Kondorura, and A. M. Halim. Vehicle Counting Quantitative Comparison Using Background Substraction, Viola Jones and Deep Learning Methods, in 2018 IEEE 9th Annual Information Technology, Electronics and Mobile Communication Conference (IEMCON), pp. 8, 2018.

20. B. Hardjono, B. Hardjono, M. G. A. Rhizma, A. E. Widjaja, H. Tjahyadi, and M. J. Josodipuro. Vehicle Counting Evaluation on Low-resolution Images using Software Tools, in 9th International Conference on 
Information Communication and Management (ICICM), pp.6, 2019.

21. T. Hariguna, \& Akmal,“Assessing students’ continuance intention in using multimedia online learning", TELKOMNIKA (Telecommunication Computing Electronics and Control), 17(1), 187-193, 2019. http://doi.org/10.12928/TELKOMNIKA.v17i1.10328

22. U. Rahardja, A. Moeins, \& N. Lutfiani, "Leadership, competency, working motivation and performance of high private education lecturer with institution accreditation B: Area kopertis IV Banten province", Man in India, 97(24), 179-192, 2017.

23. T. Hariguna, Berlilana, \& R. Wibowo, "Understanding the impact of multimedia education on autism students an empirical study", Proceedings of the 3rd International Conference on Communication and Information Processing - ICCIP '17, 2017. http://doi.org/10.1145/3162957.3163004

24. M. Tawarish and K. Satyanarayana, "A Review on Pricing Prediction on Stock Market by Different Techniques in the Field of Data Mining and Genetic Algorithm," Int. J. Adv. Trends Comput. Sci. Eng., vol. 8, no. 1, pp. 23-26, 2019.

https://doi.org/10.30534/ijatcse/2019/05812019

25. P. Singh and N. S. Gill, "A Secure and Power-Aware Protocol for Wireless Ad Hoc Networks," Int. J. Adv. Trends Comput. Sci. Eng., vol. 8, no. 1, pp. 34-41, 2019. https://doi.org/10.30534/ijatcse/2019/07812019 